\title{
UTOPÍA Y ARCADIA \\ EN LOS RELATOS DE ALICE DIXON LE PLONGEON
}

\author{
ROMINA ESPAÑA \\ Carolina Depetris \\ Dirección General de Posgrado \\ Centro Peninsular en Humanidades y Ciencias Sociales \\ Universidad Nacional Autónoma de México
}

\begin{abstract}
Resumen: El propósito de este trabajo es presentar dos posibles modelos epistémicos, entendidos como modelos de interpretación y representación de una realidad, que acompañaron a Alice Dixon Le Plongeon en su viaje por la península de Yucatán en la segunda mitad del siglo xIx. Para ello nos centramos en los artículos recopilados por ella en Here and there in Yucatan (1886): analizamos la reconstrucción del pasado maya en términos utópicos y la consideración del Yucatán contemporáneo en términos arcádicos. Ambos modelos sirven a la autora tanto para valorar la realidad mayanse como para criticar la degradación de las sociedades modernas occidentales de las que ella formó parte.
\end{abstract}

Palabras clave: Yucatán, Alice Dixon Le Plongeon, utopía, arcadia, representación.

AвstRAct: The purpose of this paper is to present two possible epistemic models understood as models of interpretation and representation of a reality that accompanied Alice Dixon Le Plongeon on her trip around the Yucatán Peninsula in the second half of the 19th century. To do so, we focused on the articles which, she herself, compiled in Here and there in Yucatán (1886). In them we analyzed the reconstruction of the Mayan past in utopian terms, and the consideration of contemporary Yucatán in arcadian terms; the writer finds both models useful, not only to appraise Mayan reality but also to criticize the degradation of occidental modern socities of which she was part.

Kerwords: Yucatan, Alice Dixon Le Plongeon, utopia, arcadia, representation.

RECEPCIÓN: 27 de agosto del 2010.

ACEPTACIÓn: 27 de enero del 2011. 



\title{
UTOPÍA Y ARCADIA EN LOS RELATOS DE ALICE DIXON LE PLONGEON
}

\author{
ROMINA ESPAÑA \\ Carolina Depetris \\ Dirección General de Posgrado \\ Centro Peninsular en Humanidades y Ciencias Sociales \\ Universidad Nacional Autónoma de México
}

Acompañando a su esposo, el conocido estudioso de temas mayanses Augustus Le Plongeon, Alice Dixon (1851-1910) llega a Yucatán en 1873 y, durante un viaje de once años, fotografía la península, lleva un diario y escribe una serie de artículos que publica en diferentes medios de Estados Unidos y que, en forma de libro, salen a la luz en 1886 bajo el título Here and there in Yucatan. ${ }^{1}$ En el prefacio dice:

During a sojourn of several years in Yucatan, traveling here and there, stopping where we found interesting vestiges of the Mayas, the highly-civilized ancient inhabitants of that country, we had every opportunity of mingling with the natives. Thus we became acquainted with their mode of life, religion, sacred rites, superstitions, fables and traditions; as well as learning something of their philosophy, and observing how communism is practiced among them (Dixon, 1889: prefacio s/n página).

En esto que Gérard Genette denomina "instancia prefacial" y que por ser un "prefacio autoral asertivo original" tiene la función de guiar una buena lectura del texto que anuncia, Dixon valora su testimonio como un aprendizaje. ${ }^{2}$ Lo que Alice asimiló sobre la cultura maya durante el tiempo que estuvo en contacto con ella es, declara poco más adelante, lo que nos va a contar. Ahora bien, en su

\footnotetext{
${ }^{1}$ Antes de la publicación de esta obra, la viajera ya había publicado 15 de las 18 piezas que se incluyen en el volumen. Ocho de los artículos fueron impresos antes de 1886 en revistas reconocidas por el ámbito científico como el New York World y los Proceedings de la American Antiquiarian Society. Los tres relatos del libro que no aparecieron con anterioridad son "Along the Coast", "Idolatry in Yucatan" y "Fables told by the Mayas Indians".

${ }^{2}$ Un prefacio es, para Genette, "toda especie de texto liminar (preliminar o posliminar) autoral o alógrafo, que constituye un discurso producido a propósito del texto que sigue o que precede" (2001: 137). Un "prefacio autoral asertivo original" es aquel que tiene como función principal asegurar la buena lectura de texto según el siguiente esquema: "1. obtener una lectura" del texto propuesto y "2. obtener que esta lectura sea buena" (2001: 168). Estos dos objetivos, sostiene Genette, "están evidentemente ligados al carácter autoral de este tipo de prefacio [...], a su carácter original [...], y a su emplazamiento preliminar, y por lo tanto monitor: he aquí cómo y por qué usted debe leer este libro. Implican entonces, y a pesar de todas las denegaciones de uso, que el lector comience por leer el prefacio" (2001: 168).
} 


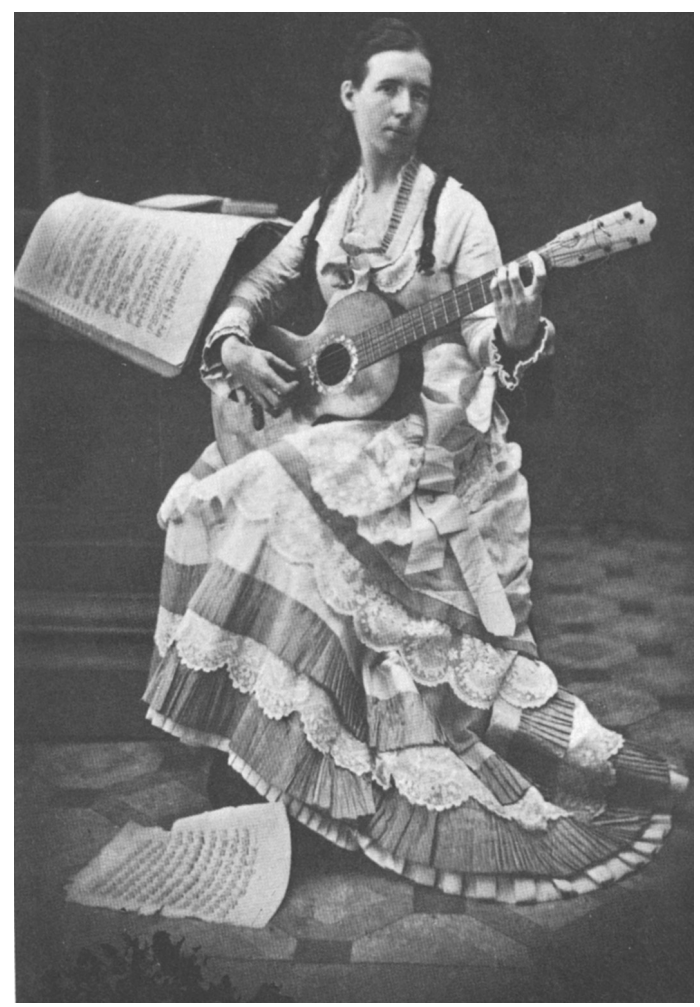

Figura 1. Alice Dixon Le Plongeon (c. 1875), posiblemente en Mérida. Foto: Desmond, 1988: 12

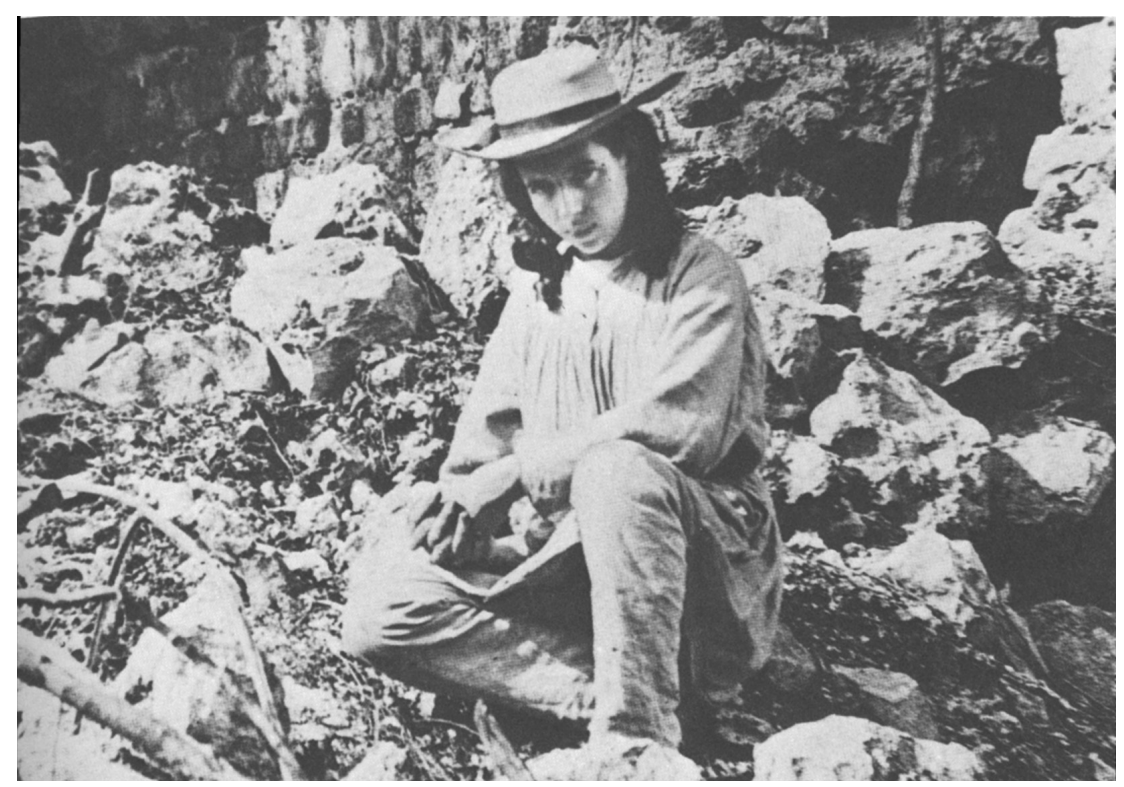

Figura 2. Alice Dixon Le Plongeon a los 22 años en las ruinas del Akab Dzib en Chichén Itzá. Foto: Desmond, 1988: 19 
encuentro con Yucatán, en su relación con ese mundo sustancialmente ajeno a su cultura sajona, Alice Dixon dice que es gracias a la convivencia con los nativos como ella y su esposo llegan a conocer el modo de vida, la religión, los ritos sagrados, las supersticiones, fábulas y tradiciones de los mayas. Esto a los lectores nos hace suponer que ese aprendizaje deriva de una aprehensión directa de un lugar hasta entonces desconocido para ella: su discurso, marca verbal del saber adquirido, deriva del dictado inmediato del objeto de observación y estudio (el mundo maya peninsular); esto es, no a priori. Acto seguido, Dixon cruza una categoría propia de una realidad (la suya) con otra (ajena): el comunismo. Antes de entrar a la lectura de los relatos que componen su libro, la aparición del comunismo en el prefacio (asociado con una característica sustancial de los pueblos yucatecos) nos hace suponer que Dixon, en su declaración de propósitos, oblitera el hecho retórico básico de que, al configurar su experiencia de viaje en un discurso, la está representando; esa representación es el resultado de una percepción y vivencia marcadas por una episteme, esto es, por un conjunto de conceptos y categorías de pensamiento que dirigen la interpretación de dicha realidad y que la redefinen al enunciarla.

Alice Dixon llega a Yucatán guiada, de una parte, por una idea cíclica de la historia de la humanidad que adopta en sus relatos la forma de aquello que Nigel Leask (2004) denomina "temporalización" del viaje: su traslado geográfico está tutelado, incluso a veces reemplazado, por una traslación hacia el tiempo pretérito del lugar. Pero también, veremos, la temporalización es responsable de las representaciones "primitivas" del Yucatán contemporáneo a su viaje, que forman parte de una intensa curiosidad etnográfica anclada en el tiempo presente que está, en su caso, muy fuertemente subrayada en el programa fotográfico que impulsa su viaje junto a Le Plongeon. Así, pasado y presente son las dos dimensiones temporales que ocupan el interés de nuestra autora y que continuamente alternan en sus artículos. ${ }^{3}$ Ambas líneas de tiempo están sujetas a una episteme específica que define la comprensión y representación de la realidad tanto histórica como contemporánea de Yucatán. Esta episteme se configura y manifiesta, a nuestro juicio, en dos temas de larga tradición literaria: la utopía, que se desenvuelve en la dimensión pretérita de los relatos de Dixon; y la Arcadia, que acompaña el encuentro de Dixon con el Yucatán contemporáneo. Así, utopía y Arcadia confluyen, en los testimonios de la autora, en una configuración literaria de Yucatán con rasgos muy específicos que, veremos, desemboca en un fuerte discurso crítico de su propia realidad moderna occidental pautado tanto por la nostalgia del pasado como por la angustia ante el porvenir.

Antes de comenzar nuestro análisis es necesario mencionar algunos datos sobre la vida de Alice Dixon Le Pongeon. Como señala Lawrence Gustave Desmond

\footnotetext{
${ }^{3}$ En su diario apunta en noviembre de 1874: "In the beginning of the month we thought of starting for Chichen Itza, stopping a short time at each of the places through which we passed so that we might know Yucatan modern as well as ancient" (apud Desmond, 2009: 46).
} 
(2009) en su libro Yucatán Through Her Eyes, ${ }^{4}$ Dixon nació el 21 de diciembre de 1851 en Londres, donde desde sus primeros años compartió el interés por la fotografía con su padre, Henry Dixon, quien en su época fue un reconocido fotógrafo de objetos de museos y de edificios históricos, y contribuyó en el desarrollo tecnológico de la fotografía. Gracias al entrenamiento que recibió de su padre, esta disciplina fue un complemento imprescindible en su escritura de viaje.

Alice Dixon tuvo su primer acercamiento a la historia y cultura de los antiguos mayas alrededor de 1871 en Londres, a través del contacto con las ideas de su futuro esposo, Augustus Le Plongeon. Estas concepciones fueron desarrolladas por Augustus durante su viaje por el Perú y fueron motivadas como parte de su interés por conocer el origen del Nuevo Mundo, específicamente el de los antiguos mayas de Yucatán que consideraba los fundadores de Egipto. Dixon también revisó otras obras sobre Yucatán, incluyendo el célebre libro de viaje de John L. Stephens, Incidents of Travel in Yucatan, que desde su publicación en 1843 fue uno de los relatos más importantes sobre los antiguos mayas y el Yucatán del xix. Asimismo, dentro de su repertorio de lecturas sobre la historia de esta península, se encontraban las importantes crónicas de fray Diego de Landa, Relación de las cosas de Yucatán, y de Diego López de Cogolludo, Historia de Yucatán, ambas citadas en Here and there in Yucatan.

\section{Utopía}

Según señalan algunos autores como Dubois, Hartig y Soboul (apud Trousson, 1995: 23 y ss.), la utopía es, antes que un género literario definido, la expresión de un "espíritu utópico", una mentalidad específica presente en todas las épocas. Esta "necesidad de utopía", como sostiene Aínsa, este "utopismo", como lo denomina Trousson, es parte de un principio de esperanza esencial que hace de la utopía antes que un género literario, una función constante de expresión variada, marcada por las adaptaciones y alteraciones en la forma y contenido según lo dictan las necesidades de su contexto. Así, debemos pensar, primero, el utopismo de Dixon en un momento en donde la visión nostálgica del pasado propia del Romanticismo todavía tenía cierta influencia, especialmente aplicada a sociedades que no seguían el ritmo acelerado que imponía la modernidad derivada de la revolución industrial y, segundo, a la luz de la crisis de las utopías que caracterizará el nihilismo y decadentismo de finales de siglo. ${ }^{5}$

\footnotetext{
${ }^{4}$ En este libro Desmond publica las notas de campo que Alice Dixon escribió durante su primer viaje a Yucatán, las cuales permanecieron perdidas, junto con otros materiales de la viajera, hasta su descubrimiento en 1999, cuando el Getty Research Institute en Los Ángeles adquirió una colección de los documentos de Alice y Augustus Le Plongeon.

${ }^{5}$ La utopía a finales del XIX sufrió una transformación en sus lineamientos. Durante la segunda mitad de dicho siglo (1860-1914) proliferó la utopía socialista. Esta y otras de dicho periodo soñaban con un mundo mejor donde los hombres vivieran libres del maquinismo y bajo la norma de la
} 
El origen del término utopía está estrechamente vinculado con los viajes: es Raphäl Hythlodée quien, de regreso de sus navegaciones junto a Vespucio, conoce supuestamente a Moro a través de Pierre Gilles, corrector de la editorial Thierry Martens, encargada de publicar en 1516 De optimo republicae statu deque nova insula Utopia. Hythlodée evoca ante Moro sus derroteros y dedica especial atención a la isla de Utopía, donde permaneció algún tiempo. Se desconoce la ubicación de la ínsula, pero toda su organización permite a Moro, a través de la voz de Hythlodée, proponer en el libro II un modelo de sociedad ideal, muy contrastada con la sociedad inglesa moderna cuya crítica estructura el libro I. La etimología del término utopía refuerza la doble carga semántica del vocablo ideal: del griego ou-topos, "ninguna parte", y eu-topos, "lugar feliz". ${ }^{6}$

Como género literario, sin embargo, la utopía tiene un origen anterior a la Europa moderna. Platón, en Timeo y Critias, describe un país imaginario cuyos habitantes viven bajo una organización política ideal. ${ }^{7}$ En estos diálogos Platón desarrolla el mito de la Atlántida, referente crucial, veremos, en la teoría sobre el origen de los mayas que esgrime Augustus Le Plongeon y que secunda su esposa. En Critias, diálogo inconcluso, es donde Platón nos presenta una descripción minuciosa de la geografía y organización del Estado atlante. Vamos a condensar estas características: se trata de una isla rica en metales, con abundante fauna salvaje y domesticada, abundantes pasturas y vegetales. El sitio era favorecido por el Sol y "producía toda clase de cosas bellas y admirables y en una cantidad ilimitada" (115b); no falta el agua y el comercio es intenso y continuo. El diseño de la ciudad está trazado de manera simétrica, teniendo como eje el palacio del rey. Los habitantes obedecen las leyes recibidas, respetan el bien común, son moderados, sabios, virtuosos y despreocupados de los bienes materiales.

igualdad y la justicia. Particularmente en Inglaterra la abundancia de estas obras prolongó por mucho tiempo un socialismo sentimental y utópico, alejado de la verosimilitud económica y social. A finales de este siglo, los utopistas empezaron a inquietarse por la viabilidad de la utopía. Por lo tanto, sus obras se convirtieron en una impugnación del porvenir lejano de la humanidad. Así nació la idea de que el institucionalismo utópico no aportaba la solución definitiva y surgió un escepticismo profundo respecto a la naturaleza humana presa de su destino.

${ }^{6}$ En una supuesta composición de Anemolio, poeta sobrino de Hythlodée, sobre la isla de Utopía, texto que antecede a los dos libros que componen la obra de Moro, se lee: "Utopía era mi nombre, / Es decir, un lugar adonde nadie se dirige. / Compárome con la República de Platón / Aunque soy quizás en este campo vencedora; / Porque aquella era sólo un mito en prosa, / Pero sobre lo que él escribió yo soy ahora, / En hombres, riqueza y ley consolidada, / Un lugar adonde todo hombre sabio se encamina: / Eutopía es hoy mi nombre" (Moro, 2003: 45). Blanco Martínez explica cómo Moro complica aún más la semántica del término cuando en una carta al humanista Guillaume Budé incorpora el vocablo udetopía, que significa "país del nunca jamás" (1999: 17).

7 Trousson sostiene que en República y Las leyes aparecen muchos principios que, luego, serán recurrentes en el género, aunque estos dos últimos diálogos no son utopías sino proyectos de legislación. El investigador destaca estos principios: justicia, fuerte sentido de comunidad y consecuente proscripción del interés individual, sencillez y felicidad, matrimonios controlados por el Estado, educación a cargo del Estado, sociedad estructurada. Para que fuesen utopías faltó, dice Trousson, que Platón nos mostrara en estos diálogos la sociedad en pleno funcionamiento ( $c f$. 1995: 58 y ss.). 
Varios son los relatos utópicos que siguen al de Platón, especialmente en la época alejandrina debido, justamente, al estímulo para la imaginación que supuso la sospecha de la existencia de tierras y sociedades desconocidas más allá de la India. Según Trousson, un relato clave (ya que fue una fuerte influencia para Moro) es el de Yámbulo, autor del que nada sabemos salvo por el resumen de su obra que hace Diodoro en Biblioteca histórica. Por su comentador nos enteramos que Yámbulo llega náufrago a una isla "redonda de forma y con un perímetro de unos cinco mil estadios” (II, 55, 6). Allí descubre un Estado donde sus ciudadanos ejercen por turno las funciones públicas y que está fuertemente presente en toda la organización cívica y social, al punto de regular por decreto desde los matrimonios hasta los menús diarios. En el testimonio de Yámbulo, sostiene Trousson, ya aparecen todos los elementos del relato utópico clásico: "viaje imaginario, naufragio, sin olvidar el prurito de precisión geográfica, visita del país de Utopía por el extranjero maravillado, descubrimiento progresivo del modo de vida, de la organización social y política" (1995: 69).

No son otros los elementos que están presentes en el viaje junto a Vespucio que relata Raphaël Hythlodée a Moro: ${ }^{8}$ hay una planificación minuciosa de la isla de Utopía, tanto en su trazado como en su organización estatal. Cada ciudad tiene idéntico diseño, con igual número de edificios; está habitada por seis mil familias, cada una con cuarenta miembros. El sistema político es parlamentario, la base económica es agrícola, no existe la propiedad privada y si alguna población tiene un año exceso de producción, la cede a otra más necesitada. Exceso, precisamente, es lo que no se admite en Utopía: el lujo es muy mal visto, la producción se reduce a lo estrictamente necesario; si una familia tiene demasiados hijos los cede a otra; si una ciudad está sobrepoblada, el excedente poblacional se transfiere a otra. El ascetismo, la frugalidad y el equilibrio son principios esenciales de las sociedades utópicas. Todos trabajan, ya que el ocio sólo es admitido para educarse o hacer música, pero jamás para obtener ganancias con ello: los suministros alimenticios, por ejemplo, se obtienen sin intercambio de dinero porque son considerados un bien común. El cuidado de la salud también es derecho de todos. En definitiva, en Utopía hay una comunidad apacible, fraterna, que vive según una ley de orden natural que no es otra, para ellos, que la única ley racional posible.

De algunos de estos elementos inherentes al género utópico se vale Alice Dixon para descubrir y recrear el pasado precolombino de la historia maya. Estos elementos subyacen en los siguientes motivos: la Atlántida, el colectivismo, la ley natural, la sociedad sabia y las ceremonias. Vamos a explicarlos.

En el marco de la prolongada polémica en torno al origen de los pueblos mayas, Augustus Le Plongeon y Alice Dixon sostienen fuertemente la posibilidad

${ }^{8}$ No es casual, a nuestro juicio, que Yámbulo tuviera influencia sobre Moro; históricamente, ambos coinciden con dos empresas viajeras que revolucionaron el conocimiento y los límites de la imaginación: la campaña de Alejandro Magno hacia Oriente y el viaje de Cristóbal Colón a América. 
de que éstos fueron los primeros habitantes de la Atlántida. La hipótesis de un origen atlante de los pueblos americanos aparece ya frecuentemente en el siglo xvII, como queda explícito en Política indiana, donde Juan de Solórzano y Pereyra compendia todas las teorías que circulaban ampliamente en dicho siglo sobre la cuestión: "Otros dicen, que pudieron pasar á ellas desde aquella Isla Atlántica, que refiere Platón en su Thimeo, y en esta opinión está muy firme Justo Lipsio [Phisiolog., 2, 19]; siendo así que los que mejor sienten, tienen esta Isla, y toda la narración de Platón por patraña" (57). No es una hipótesis fuerte en el siglo xvIII pero resurge en el xIx, primero gracias a Guillermo Dupaix, quien en 1807 sostiene: "En cuanto al establecimiento parcial de la dicha nación palencana, no repugna a la sana razón suponer que esta emigración fuese procedente de la parte oriental del globo, y dimanada de la grande Isla Atlántida” (1830: 314). Idéntica posibilidad sostiene Brasseur de Bourbourg, y esta nos conecta con Augustus Le Plongeon. En 1869, después de dos años de estudio de un manuscrito maya que le mostrara don Juan de Tro y Ortolano, Brasseur publica lo que se conoce como Codex Troano. ${ }^{9}$ Para Brasseur, este manuscrito maya describe la desaparición de la Atlántida y es el códice que sustenta la hipótesis de Augustus Le Plongeon.

En el Codex Troano, Le Plongeon lee una historia dinástica que consiste en que los antiguos mayas partieron del Occidente (Yucatán) para poblar la Atlántida (nombrada en el códice como $\mathrm{Mu}$ ) en épocas muy remotas. En la isla vivieron una época de gran esplendor y desarrollo que coincide en el tiempo con la historia que conocemos por Platón. Quince años antes del cataclismo que hundió a la Atlántida para siempre como castigo por la corrupción y decadencia del imperio, algunos de sus pobladores regresaron a la patria, es decir, a Yucatán, donde iniciaron un nuevo periodo de su historia. La civilización de Yucatán fundó un imperio nuevo que logró alcanzar gran desarrollo y, tal como comenta Dixon en el prefacio de $A$ dream of Atlantis, ${ }^{10}$ legó a nuestra época los restos materiales que dejan ver tal esplendor.

Para Alice Dixon es en los antiguos libros mayas donde se encuentra gran parte de los secretos históricos y científicos de esta civilización. Entre los libros que se salvaron de ser quemados por Landa, Dixon se detiene en el ya mencionado Codex Troano que, según Augustus Le Plongeon, constituye una obra sobre geología y etnología en la que también se da importancia a la historia antigua de los mayas, principalmente de la familia Can. Para Dixon, la descripción que se hace de la familia Can en el códice, "corresponding exactly to what we have discovered, regarding that royal family, in our study of the ancient paintings and inscriptions" (Dixon, 1889: 115). Dixon también identifica en el códice el

\footnotetext{
${ }^{9}$ El Manuscrit Troano: études sur le système graphique et la langue des Mayas, que Brasseur publicó en 1869 en París, fue el que Augustus Le Plongeon citó en su polémica obra Queen Móo and the Egyptina Sphinx para desarrollar sus ideas en torno al origen atlante de los mayas.

${ }^{10}$ En los últimos años de su vida, Alice Dixon escribió este poema largo que apareció seriado en la revista de la Theosophical Society, The World, entre los años de 1909 y 1911, poco después de su muerte ( $c f$. Desmond y Messenger, 1988: 120).
} 
registro de cataclismos "by which the face of the earth has more than once been changed, owing to the submersion of some lands, and the upheaval of others", desastres naturales que confirman "the story of the disappearance of a great island, Plato's Atlantis, in the Atlantic ocean" (Dixon, 1889: 115). ${ }^{11}$

En esta hipótesis del origen mítico de Yucatán la utopía clásica está cruzada por las ideas sobre el progreso de los grupos humanos del socialismo utópico francés. En la forma clásica del género, el viajero que llega a la isla utópica lo hace siempre en un tiempo presente signado por el esplendor. Como sostiene Trousson, "la utopía es en un presente definitivo que desconoce el pasado e incluso el porvenir, pues, al ser perfecta, ya no cambiará. La utopía realizada, edificada en nombre del progreso absoluto, niega toda posibilidad de progreso ulterior: es resueltamente inmovilista, definitiva, al abrigo del tiempo" (1995: $45)$. En la hipótesis que sostiene Dixon, la historia de los mayas comienza justamente en la era de máximo desarrollo del continente platónico; luego la autora señala un periodo de decadencia que se relaciona con la desaparición de la Atlántida, dando lugar a una nueva etapa de desarrollo de la civilización maya que comienza a declinar poco antes de la llegada de los españoles y que, en el siglo xix, aún continúa en dicho proceso crítico como resultado de los años de la Colonia y la intervención de Occidente. Esta idea cíclica de la historia que subyace a las hipótesis de Dixon se nutre, a nuestro entender, de la consideración del devenir histórico de Henri de Saint-Simon quien, consciente de la profunda transformación que despuntaba con la era industrial, sostuvo, muy en la línea de la Ilustración, cómo la historia de los hombres está regida por una ley de progreso pero, y he aquí el rasgo esencialmente romántico de su teoría: ese progreso no es lineal sino, precisamente, una secuencia alterna de lo que él denominó "periodos orgánicos" y "periodos críticos". ${ }^{12}$

${ }^{11}$ La Atlántida es uno de los muchos mitos que retoman el tema del diluvio y que por siglos generó temor entre los hombres. Desde el siglo xvII hasta el xIx, el diluvio fue "interpretado como una fractura espacio temporal y, al mismo tiempo, como un camino de salvación de la humanidad. Detrás de aquella catástrofe asomaba el signo de alianza o de nueva alianza entre Dios y el hombre", pues se consideraba que "los diluvios universales destruyen formas de vida que no agradan a las potencias divinas" (Milani, 2007: 175).

${ }^{12}$ Hay en la obra de Saint-Simon, como también lo hay en la de Herder y luego en otras del pleno Romanticismo, una reivindicación de los periodos "oscuros" de la historia, como la Edad Media. Para él, una época es orgánica cuando el conjunto de principios sobre los que se fundamenta es muy sólido, y crece y actúa en el interior de esa época. Así, el medioevo cristiano fue una época orgánica y estable regulada por la fe como fundamento sólido. Hay, no obstante, momentos en la evolución de una sociedad en que algunas ideas, algunos valores, algunas técnicas, etc. comienzan a invalidar los principios sobre los cuales se había fundamentado y la estabilidad interna se rompe, generando un momento crítico, una "época crítica". Saint-Simon, junto con Charles Fourier, Pierre-Joseph Proudhon y Robert Owen fueron los representantes de lo que Engels denominó luego "socialismo utópico", en oposición al "socialismo científico" de Marx. El carácter utópico, más allá de que estos autores proponían sistemas de organización social muy cercanos a los propuestos por la utopía clásica, reside en la confianza en que a una época crítica seguirá invariablemente una orgánica. 
El gran imperio maya fue fundado, entonces, por los descendientes de la Atlántida, particularmente por el príncipe Can, quien fue nombrado rey unánimemente por los nuevos atlantes. El sabio Can había sido primo y amistoso consejero del rey de la Atlántida, Atlas, y fue quien encabezó la migración a la tierra de "Mayach" (Yucatán) por motivos éticos, ya que rechazaba las condiciones en las que el nuevo rey, Gadeirus, había tomado posesión del imperio. ${ }^{13}$ En esta tierra de la que habían partido originalmente a fundar la Atlántida, y a donde volvían, los mayas estaban tan absolutamente "free from greed of wealth as are their unfortunate and degraded descendants" (Dixon, 1889: 101) y allí vivían en un estado de altruismo que Dixon califica como "a system of communism" (Dixon, 1889: 100).

El tema de la vida en comunidad es una de las premisas más importantes para la utopía clásica, ya que en ella se funda el orden social de los estados utópicos. ${ }^{14}$ En el Yucatán pretérito que reconstruye Dixon (anterior al tiempo de la Conquista española), "the land was common property; all worked together to cultivate it, dividing the product equally, after presenting a part to their caciques" (Dixon, 1889: 104). Este trabajo colectivo, como en toda sociedad utópica, está esencialmente basado en la agricultura, y los alimentos cultivados son repartidos equitativamente. También menciona que los mayas "never thought of cheating each other" (Dixon, 1889: 104) pues, al igual que los habitantes de Utopía, jamás buscaban sacar ventaja de alguna situación porque no existía la codicia entre ellos.

Para Dixon, los mayas vivían en "a universal brotherhood" (Dixon, 1889: 104) que les permitía interactuar entre ellos y con los de fuera como si se tratara de una gran familia. Así, "when one went traveling he was welcome in every house, sheltered and fed as a matter of course, nobody thinking of asking or accepting payment" (Dixon, 1889: 104). Esta es una traslación casi directa de pasajes de la obra de Moro en los cuales Hythlodée menciona que los viajeros no tenían pertenencias porque en todas partes estaban como en su casa; o de la Nueva Atlántida, de Bacon, donde se recibe a los viajeros que naufragaron y en ningún momento los pobladores de la isla de Bensalem aceptan el pago que los extranjeros les

\footnotetext{
${ }^{13}$ Dixon comenta en A dream of Atlantis el caso del corrupto príncipe Gadeirus, quien envenena al rey del continente, Atlas, para quedarse con su reinado.

${ }^{14}$ Existen diferencias considerables entre la idea de república en Moro y Campanella: mientras que la comunidad paterna cristiana de Moro está fundada en el oficio humano, en la obra de Campanella se convierte en una comunidad ideal de ser, tal como ocurre en los textos de Platón. En realidad, Moro y Campanella sólo logran tomar en cuenta los problemas éticos que plantea Platón traduciéndolos en términos sociales. El hecho de que para los griegos dicho filósofo excedía el campo de la política, predispone a que se le haya retomado en el siglo xvI, ya que insistía en darle al Estado una fuerte unidad. Sin embargo, tal como explica Moreau: "La ciudad platónica sólo conoce el comunismo bajo el primado de una división de clases (sólo existe en la clase de los gobernantes) y sirve esencialmente para resolver los conflictos éticos entre los hombres, más exactamente entre los hombres de la clase superior" (1986: 26). Este modelo platónico perpetúa la sociedad de clases, mientras que la utopía clásica intenta suprimirla.
} 
ofrecen por sus admirables atenciones. Cabe señalar que Alice enfatiza que la hospitalidad de los mayas es un elemento de continuidad entre su pasado civilizado y sus descendientes contemporáneos a las exploraciones de la viajera. ${ }^{15}$

Opera también en Dixon una fuerte conciencia de la importancia de la "ley natural" en la comunidad de los mayas antiguos frente a la ley positiva o escrita: "Written bonds were not in use among them, for none dreamed of breaking their word" (Dixon, 1889: 104). Esta característica es común a los utopianos descritos por Moro, para quienes "la naturaleza humana constituye un tratado en sí misma, y los seres humanos están unidos de un modo mucho más efectivo por la benevolencia, más que por los contratos, por los sentimientos, más que por las palabras" (2003: 159). Ante todo, las leyes en Utopía, según explica Moro, propician un mundo sin legislación inútil. A partir de este principio, la viajera ubica en el antiguo imperio maya un fundamento básico de la utopía: la naturaleza y la sociedad siguen las mismas leyes. Este axioma orienta la siguiente cita en "Philosophy of an Indian sage": "The law-givers of each land will assure thee that right is to obey their mandates; and will chastise any divergence from them; while Nature, inexorable, will instantly inflict the penalty of any disobedience to her law. Vice is to do anything that is un-natural" (Dixon, 1889: 135). Es por eso que la ley utópica es buena, cierta, fácil de aprender y es un deber de todos conocerla.

Otro tema importante que Alice Dixon aborda en su reconstrucción histórica del Yucatán antiguo y que la acerca al modelo del género utópico atañe a la organización social de los mayas y al alcance de su conocimiento científico. En las utopías que siguieron la tradición platónica, como las renacentistas, este tema fue central para sostener la estrecha relación que existe entre la perfección moral y el orden social; por ello, en estas obras el gobierno de la república o del Estado suele estar a cargo de un grupo de sabios o sacerdotes que eran elegidos por el pueblo en base a su virtud. Este sabio combinaba la clarividencia con el desinterés absoluto. De igual modo, los sabios mayas descritos por Alice Dixon conformaban un grupo restringido entendido en un amplio campo de saber:

Archaeology was one of the sciences studied by the Maya wise man, which shows that the past was as a great mystery, an as attractive subject from then as it is for antiquarians of our days. They also had works on medicine, on astronomy, on chronology, and geology; theology too was treated of on their writings [...]; the art of divination and gift of prophecy were likewise considered (Dixon, 1889: 109).

Además tenían interés, al igual que los pobladores de la Bensalem de Bacon y la Utopía de Moro, en conocer la historia y los idiomas de otras partes: "They had books containing the early history of their own nation, and that of other people with whom they had had friendly intercourse" (Dixon, 1889: 109). El saber de los señores mayas, como el de los sabios de Bensalem, nunca era exhibido

${ }^{15}$ Esta característica del Yucatán moderno es matizada en sus apuntes diarios. 
en público: "they were no doubt bound not to divulge certain things revealed to them in the secrecy of initiation" (Dixon, 1889: 109). Recordemos que en la Nueva Atlántida la más valiosa joya que posee la ciudad de Bensalem no son los objetos preciosos que abundan en su tierra, sino los secretos de la casa de Salomón, como la historia de la fundación del Estado, instrucciones sobre las preparaciones y los instrumentos para el trabajo, descripciones de los empleos, de las funciones, de las ordenanzas y de los ritos.

En las sociedades utópicas, la regularidad con la que se vive cotidianamente puede permitirse ciertas variaciones únicamente en días puntuales, festivos. Aunque existen distintos modos de abordar los festejos, siempre constituyen un motivo para fomentar y resaltar la organización social de la colectividad. En Dixon se refuerza el sentido de comunidad y de hermandad universal propios del comunismo cuando explica que en el primer día Pop (primer mes del año civil del calendario maya) se celebraba una fiesta general en la que "those who could possibly afford it then had everything new - clothing, utensils, and furniture; even the household images that they venerated were provided with new garments" (Dixon, 1889: 93), y las cosas descartadas eran arrojadas fuera del pueblo o de la casa. Sin embargo, "no one thought of touching anything thus thrown away, even though they might see useful articles, and be greatly in need of them" (Dixon, 1889: 93). Antes del día de Año Nuevo era necesario acordar un estado de purificación; por eso los sacerdotes y los caballeros "abstained from all indulgence that might give them any gratification; and fasted a longer or shorter time, according to the strength of their devotion to the gods" (Dixon, 1889: 94). Estas ceremonias de purificación reiteran aquellas de Utopía, cuando antes de acudir al templo en los días finales de fiestas, las mujeres confesaban sus pecados a sus maridos y así también lo hacían los hijos con sus padres. ${ }^{16}$

\section{Arcadia}

En el espacio que Alice Dixon construye a partir de su vivencia de viaje va mostrando, a manera de recorrido, un mundo diferente al Occidente moderno. Esto lo hace deteniéndose en descripciones de cuadros etnográficos, de las costumbres y creencias de los habitantes, de la naturaleza exuberante y de las monumentales ruinas del pasado maya. Estas descripciones están, a nuestro juicio, marcadas por lo que Johannes Fabian (1983) denomina denial of coevalness o "negación de la contemporaneidad". Con este concepto, este autor explica que el tiempo en el discurso etnográfico está hecho para distanciar a aquellos que son

\footnotetext{
16 Trousson y Davis señalan que, en las descripciones de su estado ideal, Moro pone como modelo el de la vida monástica. Así, la vida de los utópicos se asemeja a la de los cartujos, orden cuya disciplina compartió Moro durante cuatro años. Al respecto, recordemos que Moro describe que, entre la gente de Utopía, la contemplación y alabanza de la naturaleza eran consideradas como un culto grato a Dios.
} 
observados de quienes los observan. Fabian sostiene que coevalness es un modo de relaciones temporales que no puede ser definido como un estado con ciertas propiedades, sino como una condición epistemológica que señala que todas las relaciones temporales están empapadas de una organizada praxis cultural. De este modo, negar la contemporaneidad tiene que ver con la negación de la coexistencia temporal de dos sociedades que son simultáneas, por lo que unas son vistas como "modernas" y otras como "tradicionales", "primitivas", etcétera.

Dixon marca esta distancia temporal que es, como vemos, una distancia cultural entre la sociedad "moderna" a la que ella pertenece y la realidad yucateca "primitiva", a través de un modelo arcádico del hombre maya y de la naturaleza que habita, modelo que debe mucho a la idea de "hombre natural" y de naturaleza de Jean-Jacques Rousseau (2006). Esta herramienta de distanciamiento tiene una implicación crítica que revela un profundo desencanto por el desarrollo de las sociedades modernas occidentales y de Yucatán como resultado de sus múltiples contactos con Occidente desde la época de la Conquista.

A diferencia de algunos viajeros del siglo xIx, cuya imaginación europea produjo sujetos arqueológicos "escindiendo a los pueblos contemporáneos no europeos de sus pasados precoloniales, y hasta coloniales", como señala Pratt que ocurre a principios del xix en los textos de Humboldt (1997: 237), en los relatos de Alice Dixon el "otro" coetáneo a su viaje es visto como agente histórico que tiene continuidad con sus antepasados precolombinos. Sin embargo, esta continuidad es un suceso que únicamente ocurre en la dimensión temporal del "otro", temporalidad marcada, como mencionamos, por un modelo cíclico de la historia que ubica a la civilización maya a finales del siglo xix en su momento decadente, después de un prolongado contacto con la cultura occidental y sus sociedades modernas. En contraparte, el tiempo de la viajera está definido por un presente de alto desarrollo científico y económico que difiere de la sociedad maya.

Este distanciamiento temporal entre el tiempo moderno de la viajera y el Yucatán "primitivo" de finales del xix, es lo que refuerza en ella una visión exótica del entorno recorrido que, de un lado, le origina un fuerte sentimiento nostálgico y, de otro, un acentuado extrañamiento hacia los habitantes de la región, el cual contempla un distanciamiento de la sociedad maya degradada como resultado de su contacto con la sociedad occidental. A pesar de su visión pesimista en torno a algunas de las costumbres de los mayas contemporáneos, es en el marco de la denial of coevalness en donde se fractura la contemporaneidad del tiempo histórico de la viajera con el tiempo histórico de la sociedad visitada. Como consecuencia, la pintura que Alice hace de Yucatán se sujeta a las actitudes propias del exotismo: preferir lo otro sistemáticamente al yo mismo. Por lo tanto, en esta pintura no se trata tanto "de una valoración del otro, como de una crítica de uno mismo, y no tanto de la descripción de una realidad, como de la formación ideal" (Todorov, 2003: 305). En este sentido, existe una incompatibilidad entre el conocimiento que comporta el dato histórico y etnográfico que transmite Dixon en sus escritos, y el exotismo; por eso en varias ocasiones el extrañamiento ante 
el otro desemboca en la inversión de los rasgos de quienes observan y no en la descripción de los que son observados.

Ante todo, el exotismo de Alice es el responsable de la representación del "buen salvaje" en sus obras. Esta idealización del hombre "bárbaro" comienza, en la literatura, con los grandes descubrimientos geográficos del siglo xv.. ${ }^{17}$ Es allí cuando empieza a configurarse una imagen ideal de los pueblos primitivos y la consecuente apología de la vida salvaje. Es Rousseau, sin embargo, quien le otorga al mito un valor normativo: el buen salvaje se convierte en parámetro de medición, por contraste, del grado de corrupción que ha alcanzado la especie humana en su estado civilizado. El hombre primitivo, el buen salvaje que, en palabras de Rousseau en su Discurso sobre el origen de la desigualdad, "ya no existe, quizá nunca existió, que probablemente no existirá jamás", el hombre íntegro, sano, recto, sencillo, guiado por sus sentimientos y no por la razón, por sus instintos y no por la reflexión, por la ley natural y no por la social. Desde este estado primitivo, en donde el hombre mantenía un estrecho vínculo con la naturaleza entendida como supremo criterio de valor, como arquetipo de felicidad y bien, los seres humanos han seguido un camino de decadencia que comenzó, dice Rousseau, cuando alguien dijo por primera vez "esto es mío". Con la propiedad, el hombre olvidó que la tierra es un bien común y comenzó a trazar una historia social, política, económica y cultural centrada en el provecho individual, en la falta de libertad, en la desigualdad, en la artificialidad. El progreso, en este sentido, es para Rousseau un retroceso porque aleja al hombre de su estado primitivo; en su concepción de la historia humana la cultura tiene un sentido fuertemente antitético con respecto a la naturaleza. ${ }^{18}$

Tres son los rasgos característicos de la imagen del buen salvaje que podemos reconocer en Here and there in Yucatan y que, parafraseando la obra de Lohantan, Dialogues de Monsieur Le Baron de Lahontant et d'un Sauvage dans l'Amerique (apud Todorov, 2003: 314), llamamos igualitarismo, minimalismo y naturalismo. El primero se caracteriza por la condena a la propiedad privada y la ausencia de jerarquías y de subordinación social. El segundo se refiere a la producción de subsistencia, opuesta al lujo, ya que el buen salvaje se limita a lo necesario. En cuanto al tercero: el hombre vive en conformidad con la naturaleza, prefiere la

\footnotetext{
${ }^{17}$ Este es el caso de Vespucio, quien pinta la vida de los indios de manera paradisíaca en su famosa carta Mundus novus (1503). Para él, la sociedad de los salvajes se caracteriza por varios aspectos: la ausencia de propiedad privada, de jerarquía y de subordinación, la inexistencia de prohibiciones sexuales y la carencia de religión. Estos rasgos se encuentran resumidos en la fórmula: "vivir conforme a la naturaleza" (Todorov, 2003: 308). Por su parte, Montaigne se inspiró en la descripción de Vespucio para hablar de los "caníbales". Durante los siglos xvi y xvII predominó "el esquema fijado por Montaigne: América, 'pueblo niño'” (Araujo, 1998: 46).

${ }^{18}$ En una conocida carta fechada el 30 de agosto de 1755, Voltaire le dice a Rousseau con referencia al Discurso sobre el origen de la desigualdad: "Es imposible pintar con colores más vivos los horrores de la sociedad humana. Nadie ha usado tanto ingenio para reducirnos a bestias: leyendo vuestro libro a uno le vienen ganas de ponerse a caminar en cuatro patas".
} 
igualdad y la libertad, no tiene leyes escritas porque se apega al derecho natural cuya fuente es la razón universal.

Existe una aparente paradoja en algunas de las representaciones del Yucatán primitivo como Arcadia. Esto podemos observarlo cuando Alice Dixon realiza alguna crítica del Yucatán contemporáneo a su viaje, lo cual parece romper con la semántica del exotismo que hemos señalado como característico de la negación de la contemporaneidad. Sin embargo, cabe aclarar que se trata de una crítica no dirigida a lo maya originario (el cual mantiene una continuidad con su pasado utópico), sino a aquello que ha resultado de la asimilación de la cultura occidental. Tal es el caso de la religión católica, a la cual la viajera dirige sus críticas en uno de sus relatos y culpa de la creciente idolatría que presencia en una pequeña población maya a su paso por las selvas de Yucatán: "In fact there is not a bit less idolatry among those people now, perhaps we are safe in saying that there is more, than before Christianity was introduced among them" (1889: 91). De este modo, la negación de la contemporaneidad le exige a Alice Dixon preferir como referente crítico los rasgos primitivos de la Arcadia (los cuales pueden ser pensados como pertenecientes a un estadio originario de la humanidad), a aquellos con tintes de modernidad y occidentalización. Esta dualidad de crítica/ alabanza es recurrente en Dixon, pero la consideración arcádica del hombre yucateco contemporáneo, y la utópica del pasado, sumadas a lo que veremos en el último apartado, inclinan semánticamente la balanza más hacia la preferencia de Yucatán frente al Occidente moderno con mirada hacia el futuro.

El principio naturalista que conforma la idea del buen salvaje descrito por Dixon es el elemento primordial para configurar la representación de Yucatán como una Arcadia, pues la naturaleza y el hombre maya "naturalizado" son fuertemente idealizados. Hay en las descripciones de escenas cotidianas de la vida en la península una armonía completa entre hombre y naturaleza tal como ocurre, por ejemplo, en "Along the coast", al hablar de la vida y del paisaje del pueblo de Dolores, ubicado en Isla Mujeres: ${ }^{19}$

The water of the bay was as unruffled and crystaline as a sheet of emerald; and the village of Dolores made a charming picture, with its thatched cottages, boats hauled up on the white beach, and tall palms waving like feathered canopies above the dwellings; while the perfect stillness made us almost imagine that we beheld an enchanted island awaiting the touch of a magic wand. That wand was the first golden sun-ray that shot from the east, calling every creature to life and action. Doors were thrown open; faint columns of smoke wreathed way to the cloudless sky; children ran to the beach to float their toy ships; fishermen launched their boats; women passed to and fro, and feathered songsters warbled their sweetest lay (Dixon, 1889: 5 y ss.).

\footnotetext{
${ }^{19}$ Recordemos que el encajar objetos o paisajes naturales dentro de los bordes de un marco, a manera de un cuadro o una ventana, es un estereotipo en la pintura romántica y estuvo presente en numerosas descripciones literarias desde el siglo xvIII en adelante. Más al respecto véase Milani, 2007: 100 y s.
} 
En este cuadro la naturaleza es el tema central: de ella emanan las acciones de todos los seres vivos y los habitantes no son presentados como caracteres individuales o siquiera sujetos colectivos, sino como extensiones de esa misma naturaleza. Al no confrontar cultura y naturaleza, el tema de la armonía entre hombre y medio se vuelve muy potente y se convierte en el rasgo constitutivo principal de la construcción arcádica del Yucatán que recrea la viajera en sus escritos.

Los temas relacionados con el trabajo y la solución de los problemas colectivos adoptan también un tono arcádico que destaca la abundancia de la naturaleza y la satisfacción de los habitantes con lo mínimo. En referencia a Cozumel dice la viajera:

The tickets are alive with pheasants, quails, pigeons and other game. With a little care every kind of tropical fruit, of very fine quality, grows abundantly; vanilla is found wild: plenty of copal can be gathered from the trees, as well as honey and wax, the products of harmless wild bees (Dixon, 1889: 30).

La gente, a la manera del buen salvaje, sólo toma lo que necesita del medio y nada ambiciona ya que se conforma con una vida sencilla. La condición del trabajo ligero y alegre es una de las características de la Arcadia, que encuentra su justificación en la abundancia de la naturaleza capaz de reducir el esfuerzo del hombre a su expresión mínima. La Arcadia y lo pastoral son espacios, o quizá habría que decir estados humanos que, por definición, carecen de alienación, pecado, conflicto, contradicción o trabajo. Se trata de un mundo "fresco", salido casi directamente de la mano de Dios. Allí rigen los principios del placer y de la felicidad logrados sin esfuerzo, sin melancolía, sin arrepentimiento. En este sentido, la Arcadia es el marco adecuado del hombre natural porque es algo así como un reducto dentro de un mundo caótico, desordenado, arruinado. En la Arcadia, en realidad, opera una huida de los patrones sociales que Rousseau identifica con el estado de cultura: la urbanización, la tecnología, los conflictos de clases, la vida civilizada. ${ }^{20}$

Tal vez el retrato más claro del buen salvaje se encuentra en el relato "The Caribs", donde vemos resurgir la figura de uno de los mitos de viaje más frecuentes entre los viajeros de la Antigüedad clásica, los conquistadores de la Edad Media y, por supuesto, los exotistas como Montaigne. Al igual que los caníbales de este último, los caribes de Alice Dixon reflejan el comportamiento natural en su práctica de la sexualidad y en su vida moderada. La sencillez de su forma de vida recuerda al primitivismo natural arcádico del que habla Davis, según el cual se disfruta de la abundancia natural y los deseos se vuelven moderados y son saciados fácilmente. Este comportamiento es presentado por la viajera en un pasaje donde menciona que los caribes "are polygamists, may have as many wives

\footnotetext{
${ }^{20}$ Recordemos aquí la huida ejemplar de los jóvenes florentinos desde la ciudad sumergida en la peste hacia la campiña arcádica, en Decamerón, de Boccaccio.
} 
as they can build houses for; because each must have a separate home. When a man desires to make any woman his wife he proposes to her, and, if she accepts him, clears a patch of ground; builds a hut; plants banana trees; then takes her there" (Dixon, 1889: 74).

Dos son las tradiciones literarias que convergen en la Arcadia: la edad de oro griega (por ejemplo, Hesíodo nos cuenta en Los trabajos y los días cómo allí la vida está libre de violencia y dolor, la tierra da sus frutos sin trabajo, no hay demonios y se pasa de la vida a la muerte como en un sueño); y el jardín del Edén bíblico, tema caro a los Padres de la Iglesia, a los poetas medievales y a los renacentistas. Tanto en una tradición como en la otra, se parte de un pasado esplendoroso y se cae en un presente marcado por la ausencia de ese momento pleno, por la pérdida que se espera resanar en un futuro. Este retorno del hombre a un estado de perfección original y bienestar es lo que será, en los siglos XVIII y xIx, identificado con un retorno a la naturaleza, a lo no afectado, a lo no artificial, a lo puro. Era idea común en los escritos de Rousseau y luego en el Romanticismo ver en el hombre americano, y también en el polinesio, a aquel que vivía en ese estado natural perdido por Europa gracias a los artificios de su civilización y a la consecuente corrupción. Esta tradición es la que llega hasta Alice Dixon.

La riqueza de la naturaleza arcádica que la viajera reconoce en Yucatán le permite afirmar que esta región es “one of Nature's favored spots, where there is perpetual spring, and to live in the open air is a delight" (Dixon, 1889: 28). Por eso, Dixon evoca continuamente en sus relatos escenas de pequeños pueblos y de gente dedicada a labores como la agricultura, la pesca, la caza o la recolección, y lo hace con frecuencia con un sentimiento nostálgico de la Arcadia perdida para ella, su sociedad y su tiempo.

\section{El discurso crítico: nostalgia por el pasado y angustia por el porvenir}

Vimos que en el modelo arcádico subyace una fuerte crítica a la sociedad de la que se pretende escapar. Lo mismo ocurre con el modelo utópico. Tanto el discurso crítico arcádico como el utópico ponen de relieve los males de la sociedad moderna remontando la cadena de causas que los producen y revelando, al mismo tiempo, el modo incorrecto en que las sociedades encaran dichos males como parte del proceso cíclico de su historia. Este discurso crítico explícito es consolidado por la descripción minuciosa de un modelo que funciona como parámetro comparativo y que refuerza a aquel mediante un esquema binario de valor/contravalor. La misma estructura del libro de Moro, y todo el pensamiento de Rousseau revelan este esquema dicotómico. El discurso crítico de Alice Dixon también. En sus relatos, Europa y Occidente son evocados como los lugares de pertenencia; son el aquí que idealmente se abandona en busca del allá. A partir

de la comparación con la vida y moral utópicas de la antigua sociedad maya, y 
con el estadio arcádico del Yucatán de finales del xix, el Occidente moderno, parámetro de civilización, es representado como el mundo de la decadencia moral guiado por el egoísmo, la ambición y la avaricia.

Para comprender el planteamiento crítico de Alice Dixon es necesario reconocer el diálogo que entabla con las ideas del positivismo, tan vinculadas al desarrollo industrial que generó cambios radicales en la vida social de las sociedades modernas: la multiplicación de grandes centros urbanos, el crecimiento de redes de intercambios comerciales, la acentuación de la distancia entre ciudades y zonas rurales, la disminución de mortandad entre la población gracias a los avances científicos y técnicos. Como consecuencia, surge un entusiasmo general por el inminente progreso ligado a los avances de la ciencia, la cual es considerada el único medio de solucionar los problemas del hombre y su sociedad, al mismo tiempo que garantiza el bienestar general de una sociedad pacífica y solidaria.

Esta visión positiva del futuro también puede reconocerse en algunos de los principios de la concepción histórica de Hegel: la historia del mundo atraviesa por etapas dialécticas que van definiendo un incremento progresivo tanto de la libertad como de la racionalidad. En esta última fase es donde el espíritu se realiza plenamente, lo que implica conservar el pasado como memoria y el autoconocerse absoluto en el presente. Para Alice Dixon la idea de última fase del espíritu absoluto es inconciliable con su perspectiva de la historia como proceso circular que no implica un momento culminante de progreso, sino una constante caída de las sociedades seguida de un nuevo auge siempre destinado a degradarse y volver a caer. Recordemos que en la visión exótica de Yucatán como Arcadia, en la que opera la negación de la contemporaneidad como recurso epistémico, al mismo tiempo que Alice Dixon realiza una crítica comparativa a Occidente también lo hace a algunos rasgos degradados de la sociedad yucateca contemporánea, la cual desde la Conquista ha asimilado la cultura occidental y con ello se ha alejado de su pasado utópico.

Contraria a la visión entusiasta del progreso que rige buena parte del siglo XIx, uno de los argumentos centrales de Dixon es que el desarrollo material y la civilización de las sociedades modernas propician que aquella ley natural primera se vuelva cada vez más pesada y se quebrante con consecuencias lamentables para la humanidad. Esta tesis conlleva una doble crítica: por un lado, resalta la imposibilidad del Occidente decimonónico de asimilar el modelo social ideal por excelencia que ella encuentra en el comunismo; por el otro, acentúa la condición privilegiada de la sociedad maya vista como pasado utópico en relación con el presente occidental y algunas de las características del Yucatán contemporáneo a su viaje herencia del contacto cultural con otras sociedades.

Se trata, entonces, de una crítica a aquello que no es natural o instintivo, a lo que se rige por una inteligencia ligada a la modernidad y al progreso pues resultan, como explica Rousseau, autodestructivos. Dice el indio sabio en referencia a "los seres que pueblan el mar y el aire": 
Those creatures follow that unerring guide called instinct, almost destroyed in man, who is now in a pitiable intermediate condition; having enough intelligence to enable him to make himself miserable by abusing instead of using. Alas! Will he ever be intellectual enough to seek happiness through perfect obedience to nature's laws? (Dixon, 1889: 135).

A partir de estas reflexiones, Alice Dixon cuestiona la tendencia del desarrollo occidental, y encamina a sus lectores hacia la duda respecto a la confianza en aquellos sistemas económicos y sociales que ha construido y que están basados en la potencialidad del egoísmo que tiene consecuencias nocivas para los seres humanos: "Only when men cease to love money will mankind be well off, and that time is not near at hand" (Dixon, 1889: 105).

Este pesimismo existencial característico de las contrautopías y del Romanticismo no sólo da lugar a un dualismo entre un mundo presente degradado y la nostalgia por un pasado mejor, sino que se relaciona también con el concepto de "derelicción" utilizado por J. Servier (apud Blanco Martínez, 1999: 122). Este concepto define el sentimiento subyacente en toda utopía, que consiste en la conciencia de crisis social ante la cual los hombres se encuentran impotentes. La "derelicción" en el discurso crítico de Dixon no es más que el sentimiento de angustia presente en las utopías de su época, las cuales están conscientes de la crisis civilizadora de su momento y han perdido su fe en el futuro. Para desarrollar estas ideas, la viajera emplea nuevamente al personaje del indio sabio: "that future from which, could they peer into it, many would shrink aghast, and to which others would wish to rush blindly forward to gather the yet unripe fruit that in their ignorance — poor fools! — they think will give them happiness" (Dixon, 1889: 131). Este relato, paradigmático de la razón crítica que descansa detrás de los modelos utópicos y arcádicos que sustentan la representación literaria de Yucatán, cierra con un llamado a despertar la conciencia del hombre encarnada en el personaje ingenuo de la hija que tiene fe ciega en el futuro; esto sólo podrá ser alcanzado cuando se vuelva imposible reinstalar una utopía pretérita: "Ponder my words, daughter, and if thou dost not realice them to-day, thou wilt do so at some future time when we see each other no more" (Dixon, 1889: 136).

La falta de fe en el futuro acentúa la concepción nostálgica del pasado; en ello se advierte una interesante ruptura de Alice Dixon con el socialismo utópico de Saint-Simon quien, como mencionamos anteriormente, ve en la historia la alternancia de periodos orgánicos y críticos, siendo el primero la meta de su utopismo. La crítica que Saint-Simon realiza del progreso científico no implica una añoranza del pasado y el deseo de retornar a él, sino señala la importancia de ir hacia adelante, hacia una nueva época orgánica que para aquel filósofo debe estar regida por el principio de la ciencia positiva. ${ }^{21}$ Su socialismo utópico

${ }^{21}$ Comte compartió algunas ideas con Saint-Simon, ya que fue su secretario y colaborador entre 1818 y 1824. 
contempla que en dicha nueva sociedad orgánica los hombres de ciencia son quienes tendrían el poder espiritual, en lugar de los eclesiásticos, y aquella sería el medio para alcanzar la fraternidad universal. En ese sentido, si bien tanto Alice Dixon como Saint-Simon contemplan una idea cíclica de la historia en oposición a la historia lineal, una importante diferencia entre ambos radica en que mientras para el pensador francés el momento ideal se encuentra en el progreso inevitable hacia el futuro, hacia aquella nueva etapa orgánica que permitirá la superación de la época crítica encarnada en la sociedad moderna, Alice Dixon ha perdido la esperanza en el futuro, lo que hace aún más marcada su nostalgia y añoranza por el pasado maya. Es decir, como parte de su visión cíclica de las sociedades, que contempla un periodo de auge, uno de degradación y otro de caída, la viajera preferirá la utopía situada en el pasado y la Arcadia primitiva del presente yucateco (a pesar de sus rasgos de degradación), al futuro de progreso y modernidad encarnado en el Occidente de finales del siglo xIX.

El discurso crítico de Alice Dixon no es una simple denuncia de las injusticias sociales que reconoce la autora en Occidente y también en el Yucatán de finales de siglo; es un intento reflexivo por comprender las causas de la degradación moral de la humanidad toda y las repercusiones que esto ha tenido en sus sistemas sociales. Este discurso es el catalizador de un razonamiento de índole utópico y arcádico que hemos identificado tanto en su visión "temporalizada" del pasado maya como en la negación de la contemporaneidad, episteme que soporta el acercamiento de la autora a lo otro. De hecho, esta episteme que da preferencia a lo ajeno frente a lo propio es la que estructura su crítica a Occidente bajo esta perspectiva propia del utopismo de finales del xix centrada en la angustia por el porvenir. Esta convivencia de nostalgia y angustia enmarca su visión utópica del pasado y presente de aquel lugar no-propio, situado en un distante allá espacio-temporal que se vuelve el paradigma de valoración de lo que la viajera identifica como suyo. Con esto, el razonamiento utópico y su visión arcádica de Yucatán resultan ser los mecanismos epistémicos y retóricos eficaces para que Alice Dixon represente a la realidad mayanse en todas sus dimensiones espaciales y temporales, y comprenda y resuelva la distancia cognitiva, anunciada en el prefacio de su libro, entre ella y Yucatán.

\section{BIBLIOGRAFÍA}

Aínsa, Fernando

1992 De la edad de oro a El Dorado. Génesis del discurso utópico americano. México: Fondo de Cultura Económica.

Araujo, Nara

1998 Visión romántica del otro. Estudio comparativo de Atala y Cumandá, Bug-Jargal y

Sa. México: Universidad Autónoma Metropolitana, Unidad Iztapalapa. 
Bacon, Francis

1999 "Nueva Atlántida”, Tomás Moro, Tomasso Campanella y Francis Bacon, Utopías del Renacimiento. México: Fondo de Cultura Económica, 235-273.

Blanco Martínez, Rogelio

1999 La ciudad ausente. Utopía y utopismo en el pensamiento occidental. Madrid: Akal.

Bourboug, Brasseur de

1869 Manuscrit Troano: études sur le système graphique et la langue des Mayas. París: Imprimerie Impériale.

Campanella, Tomasso

1999 "La imaginaria Ciudad del Sol", Tomás Moro, Tomasso Campanella y Francis Bacon, Utopías del Renacimiento. México: Fondo de Cultura Económica, 141231.

Davis, J. C.

1985 Utopía y la sociedad ideal. Estudio de la literatura inglesa, 1516-1700. México: Fondo de Cultura Económica.

Desmond, Lawrence y Phyllis Mauch G. Messenger.

1988 A Dream of Maya. Augustus and Alice Le Plongeon in Nineteenth-Century Yucatan. Albuquerque: University of New Mexico Press.

Desmond, Lawrence

2009 Yucatán Through Her Eyes. Albuquerque: University of New Mexico Press.

Diodoro de Sicilia

2001 Biblioteca histórica. Madrid: Gredos.

Dixon Le Plongeon, Alice

1889 Here and there in Yucatan. Nueva York: John W. Novell Company.

2001 Aquí y allá en Yucatán. México: Consejo Nacional para la Cultura y las Artes (Colección Mirada Viajera).

Dupaix, Guillermo

1830 "Viajes de Guillermo Dupaix sobre las Antiguiedades mejicanas", Antiquities of Mexico, vol. V. Londres: A. Aglio, 207-343.

Fabian, Johannes

1983 Time and the other. How Anthropology makes its object. Nueva York: Columbia University.

Genette, Gerard

$2001 \quad$ Umbrales. México: Siglo XXI.

Leask, Nigel

2004 Curiosity and the Aesthetics of Traveling Writing 1770-1840. Nueva York: Oxford University Press. 
Le Plongeon, Augustus

1896 Queen Móo and the Egyptina Sphinx. Londres: Kegan Paul, Trench, Trübner \& Co.

Milani, Raffaele

$2007 \quad$ El arte del paisaje. Madrid: Biblioteca Nueva.

Moreau, Pierre-François

1986 La utopía. Derecho natural y novela del Estado. Buenos Aires: Hachette.

Moro, Tomás

2003 Utopía. Buenos Aires: Losada.

Platón

2008 Diálogos, vol. VI. Madrid: Gredos.

Pratt, Mary Louise

1997 Ojos imperiales. Literatura de viajes y transculturación. Buenos Aires: Universidad Nacional de Quilmes.

Rousseau, Juan Jacobo

2006 Discurso sobre el origen de la desigualdad. México: Porrúa.

Solórzano y Pereyra, Juan de

s. f. $\quad$ Política indiana compuesta por el Señor Don Juan de Solórzano y Pereyra, Cavallero del Orden de santiago, del Consejo de su Magestad en las Supremas de Castilla e Indias, Tomo I. Madrid/Buenos Aires: Compañía Ibero-Americana de Publicaciones.

Todorov, Tzvetan

2003 Nosotros y los otros. México: Siglo XXI.

Trousson, Raymond

1995 Historia de la literatura utópica. Viajes a países inexistentes. Barcelona: Península. 


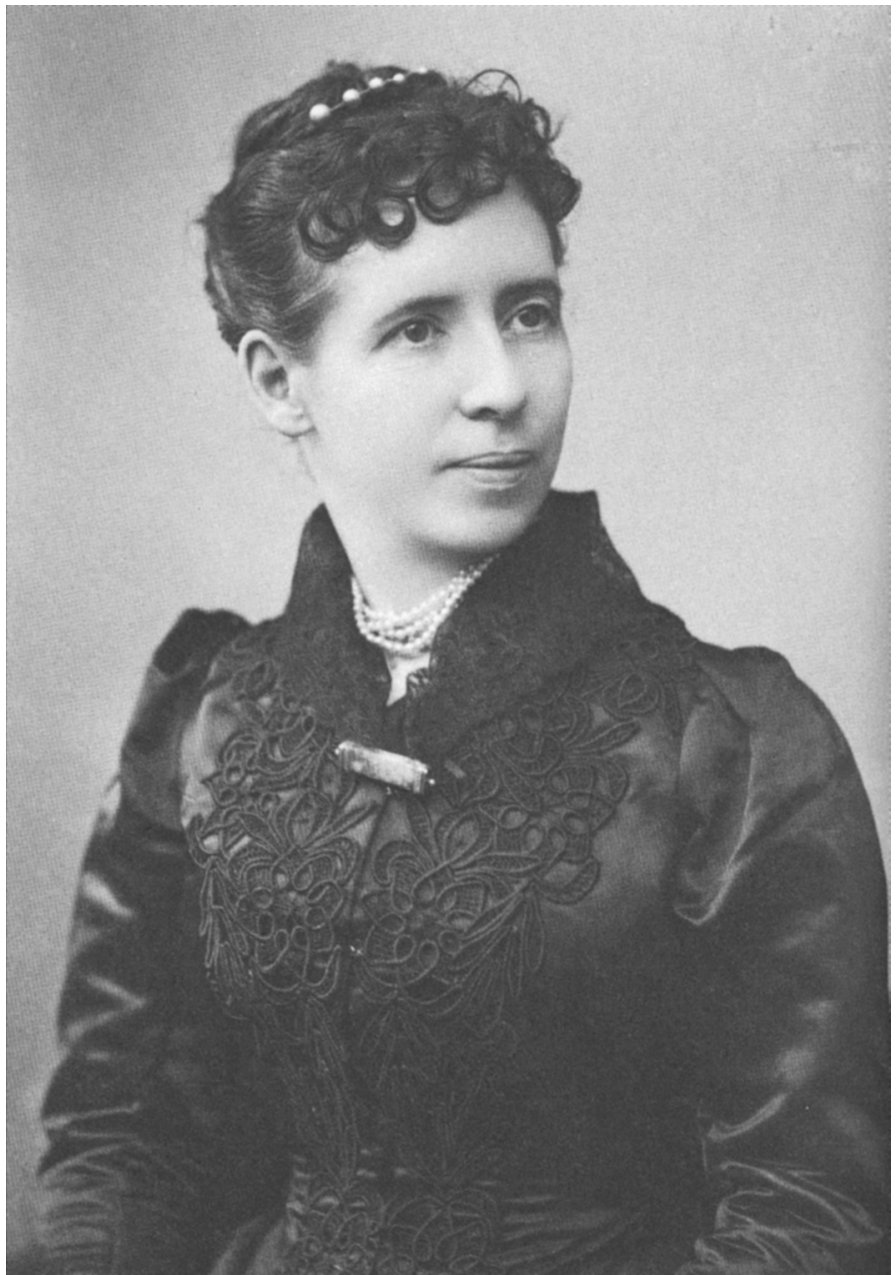

Figura 3. Alice Dixon Le Plongeon usando el talismán de la Reina Móo que Augusto le mandó hacer a partir de un tubo de jadeíta hallado cerca del Chac Mool en la Plataforma de las Águilas y Jaguares de Chichén Itzá.

Foto: Desmond, 1988: 36 